\title{
Predicaments of Accessing Rental Housing by People with Physical Disability in Dar Es Salaam, Tanzania
}

\author{
Huba M. Nguluma and Fredrick Magina \\ 1. Institute of Human Settlements Studies, Ardhi University, Dar es Salaam 35176, Tanzania \\ 2. School of Spatial Planning and Social Sciences, Ardhi University, Dar es Salaam 35176, Tanzania
}

\begin{abstract}
This paper presents study findings regarding private rental housing in urban settlements in Dar es Salaam, Tanzania with specific reference to people with physical disabilities especially the lame and handicapped. The major objective of the study was to procure deep understanding of the access to private rental housing by the lame and handicapped section of the society living in urban areas; and use of the infrastructure services related therewith. Reseach method used is case study where by interview questions were addressed to different actors. Focus group discussion, taking measurements and literature review were also used as data collection tools. The study revealed that neither the current policy nor the legal frameworks address the issue of access to rental housing by the lame and the handicapped in the prevailing private rental housing market in urban areas. Furthermore, body characteristics of the lame and handicapped, affordability of brokers fees and monthly rentals were ranked most highly among the challenges facing the lame and handicapped when searching for rental houses. The challenges pertaining to the use of the commonly shared housing infrastructure services, lack of hygiene on outdoor environment and unfavourable house and toilet/bathroom designs were noted as critical challenges related to the use of the commonly shared housing infrastructure services. The paper recommends that the lame and handicapped need to be considered as a priority and vulnerable group which need special attention in housing policy aspects. A direction of procedures to guide the lame and handicapped house seekers searching for a rental house and institutionalizing a rent regulatory body are considered paramount.
\end{abstract}

Key words: Rental housing, physical disability, affordable housing.

\section{Introduction}

Importance of housing to ones quality of life and health is often overlooked. According to Junaid et al. [1], decent housing contributes to well being, good physical and mental health, security and confidence of individuals. Housing is one of the major human rights which is deserved by each individual. However, according to UN-Habitat [2] one of the major problems facing people with physical disabilities especially the lame and handicapped is access to rental housing and use of infrastructure services. Millions of people living in African cities are tenants; and rental housing may be only a partial answer to urban housing. Rental Housing is an important housing option especially for the urban poor and

Corresponding author: Huba M. Nguluma, Dr., architect, research fields: architecture, housing and built environment. situations where people are not ready or able to buy or build houses of their own [3]. Even in developing countries like Canada, rental housing is used by a big number of low income people [4].

Public rental housing sector in Tanzania is confined to urban areas. It accounts for less than $10 \%$ of the total rental stock. The same is built to higher standards than the majority of private housing units in the city [5]. It is estimated that between $70 \%-75 \%$ of urban population is accommodated in informal housing characterized by poor housing quality, with lack of basic infrastructure like water supply, drainage systems, solid waste management systems and access road [5]. Majority of people are renting rooms in informal settlements due to shortage of affordable housing provided by the government. Housing shortage in urban settlements is a major problem facing urban dwellers in Tanzania. The estimated 
shortfall in urban areas by 2000 was 2.2 million housing units; by 2014, the deficit had grown to 3.0 million units [6].

In Tanzania today the public rental housing sector is confined to urban areas and accounts for less than $10 \%$ of the total rental stock; generally built to a higher standard as compared to a majority of private housing units in the cities [5]. The total number of public rental housing is slightly over 25,000 units, majority of which are owned by the National Housing Corporation [5]. Most of the public rental housing stock was developed specifically for employees in the government and state public corporations. The quality of housing developed in the private sector has generally tended to be inferior mainly because of being constructed in informal areas where development control and building regulation are not operative. Infrastructure is lacking and individual house owners do not have sufficient financial resources to construct a house that meets particular standards [5].

While the private sector largely in the informal settlement adds 15,000 units each year against annual demand for 120,000 units in urban areas, the public sector through National Housing Corporation has only been able to construct 300 units a year [7]. Acute shortage of affordable housing provided by the Government of Tanzania, as well as inadequate supply of formal planned plots, together with fixed development conditions, has led to majority of the common men and women to resort to room renting in informal settlements [8].

During the first decades of political independence (1960's, 1980's) few housing projects were developed by the Government with a view to improve settlement for urban dwellers in such areas as Magomeni, Ubungo, Ilala, Kinondoni, Temeke and Mwenge in the capital city of Dar es Salaam and in other towns like Morogoro, Songea, Tabora, Mwanza, Mbeya and Arusha. This has not only improved the quality of urban settlements but has also caused housing shortage. Such efforts are worth pursuing to improve informal settlements and reduce housing shortage; simultaneously, take into consideration housing needs of people with physical disability.

According to United Nations Centre for Human Settlements [9], 70\%-95\% of all new housing construction in developing countries in the past three decades was and is still being constructed in urban informal settlements [10]. With few exceptions, authorities have not paid any attention to the social and economic welfare of these areas [11]. In Tanzania, however, the population living in informal settlements has increased from $36 \%$ in 1967 to about $83 \%$ by 2003 [12]. The UN-Habitat declares that in developing countries, due to the failure of the formal land and housing delivery system, the informal housing market provides remarkable rental housing to the majority. However, it acknowledged that access to rental housing in the urban housing market has been inhibited by brokers particularly for the low-income groups. It further acknowledges that people with disabilities often face challenges in accessing housing units in this market. The question remains to be what these challenges are and what is being done in order to access rental housing in the housing market.

The UN-Habitat state that rental housing markets are influenced by, and respond to, local economic and political conditions and regulatory frameworks, and operate very differently from city to city [3]. Landlords and tenants develop and use rental housing in flexible and inventive ways to maximize the asset value of their properties and to satisfy their accommodation needs [3].

In Tanzania, the policy framework and building standards provide no substantial information on the issues of house design standards by and for the disabled. The URT [11] emphasizes on the affordable and accessibility to shelter provision whereas the URT [13] advocates for equal access to land for all. Nevertheless, with the rapid increase of rural-urban migration, it is evident that access to rental housing, 
especially for people with disabilities (PWDs) is more complex, although the right to adequate housing is recognized as an important component to human beings [8]. Logically, this is triggered by the fact that a majority of people are poor and people with disabilities use also their meagre financial resources not only for medical purposes, but also for food, clothing, education for their children and transport costs, thus ending up in renting poor quality rooms from poor houses particularly in informal settlements [8].

The World Health Organization [14] defines "disability" as an umbrella term covering impairments, activity limitations, and participation restrictions. Impairment is a problem in body function or structure; an activity limitation is a difficulty encountered by an individual in executing a task or action; while a participation restriction is a problem experienced by an individual in involvement in life situations. Thus disability is a complex phenomenon, reflecting an interaction between features of a person's body and features of the society in which he or she lives [14]. The Tanzania National Policy on Disability defines it as "a loss or limitation of opportunities to take part in the normal life of the community on an equal level with others due to temporary or permanent physical, mental or social barriers. Such a loss or limitation could be aggravated by community's perception of disabled people" [15]. Moreover, the Person with Disabilities Act defines "disability" in relation to an individual as a loss or limitation of opportunities to take part in the normal life of the community on an equal level with others due to physical, mental or social factors [16].

The World Bank and other authorities estimate that there are as many as 650 million people with disabilities around the world, making them one of the largest minority groups of marginalized people [17]. In Tanzania, there are no central established formal agreements in room renting; most agreements are reached through mutual understanding between landlords and tenants. This condition gives room to the landlords to act irrationally, some landlords attempting to harass disabled tenants due to stigma [8]. Moreover, tenants especially the lame and handicapped, are more often constrained by poor financial ability, and hence fail to pay house rents. As a result, the survival of the majority of the urban poor is threatened by among other factors, the stigma that is attached to the disability [8]. It is further observed that urban areas experience inadequate social services and infrastructure facilities, thus prompting the sharing of services like toilets, bathing and cooking areas. In the circumstances there are a number of challenges related to access to rental housing by people with disabilities.

\section{Methodology}

Two case studies namely Buguruni and Ilala wards in Dar es Salaam city were used. They were selected as case study areas because they were rich in information in the sense that they had a considerable number of PWDs (people with disabilities) as well as many institutions/associations and organizations that could assist in obtaining the needed information for this study.

Data collected were mainly qualitative and quantitative. Data collection tools used included household interviews, focus group discussions, key informant interviews, local leaders' interview, participant observation and measurements taking.

The interview that was conducted involved filling in interview questions forms where respondents from individuals, households and key informants such as officials from the CHAWATA (Tanzania Association of the Persons with Disabilities), TTA (Tanzania Tenants Association), brokers, Mtaa and Ward executive leaders were involved. Also, interview questions were administered, particularly to individual disabled household heads; household members and fellow tenants. Thirty (30) people with disabilities from each ward were purposively selected in the sub-wards. The selection based on the type of 
disability, housing ownership and occupation.

The key informants for the interview included the TTA, the ILA (Ilala Landlords Association), CHAWATA, TAMH (Tanzania Association for Mentally and Handicapped), DOLASED (Disabled Organization for Law and Social Economic Development), ICD (Information Centre on Disability), Human Rights Centre for PWDs and brokers.

Focus group discussion was also used as a data collection tool. As a way of increasing reliability of information, groups of individuals were interviewed. These included disabled household heads; males and females to document the processes they went through in accessing rental housing. The other group was that of landlords (house owners) who adopt owner and tenants occupied or rental/tenants occupied tenure arrangement with disabled and non-disabled head of family. In doing so, groups of six (6) people were interviewed from disabled households/families in order to provide their feelings and perceptions on the subject matter i.e. identifying and ranking the challenges in accessing rental housing. Additionally, they were responsible for stating the strategies adopted to overcome the challenges. In the discussion, participants were guided by the researcher's open-ended questions.

\section{Results and Discussions}

\subsection{Household Characteristics}

\subsubsection{Housing Carrier/Ownership}

In Ilala and Buguruni wards, there were two types of housing carrier. These are renting and owner occupied. Tenancy in these wards was high since they were old saturated informal settlements near the city centre, which accommodated a higher percentage of tenants. Renting houses or rooms was the main source of income for the house owners. For example, in the case of Buguruni Mnyamani sub-ward in Buguruni ward, $77 \%$ of tenants who were living in houses were mostly sharing with house owners. This phenomenon was obvious due to the fact that tenants would like to live in areas with infrastructure services (within or nearby) and employment opportunities. It was found that $92 \%$ of the total number of the lame and handicapped were tenants renting a minimum of one room to a maximum of three rooms. The rest, $8 \%$ own houses.

\subsubsection{Household Income Levels}

The study area evidenced that the lame and handicapped had lower incomes than the non-disabled. Interviews showed that, among this group of the disabled, the income levels also depended on the nature of the activity that an individual paid particular attention to. Engagement in petty trading within and outside the areas constituted the main income generating activity for most of the households. The results showed that $97 \%$ of household heads interviewed were self employed in the informal sector; and only $3 \%$ had formal employment with a regular monthly income ranging from TZS 120,000 to 300,000 depending on the level of education. $8.6 \%$ had business spaces at Mchikichini and the Machinga Complex markets whose monthly incomes in terms of profit ranged from TZS 60,000 to 90,000 . $17.2 \%$ respondents, mainly women, who were dealing with food staff activities were earning about TZS 45,000 to 60,000 in a month. Males who were engaged in shoe shining and repair who also sold mobile recharge vouchers form the majority of the group $(25 \%)$ and their monthly incomes range from TZS 45,000 to 55,000 while the rest $48 \%$ depended on barging and remittances from friends or relatives. Their incomes ranged between TZS 30,000 to 35,000 per month. This means that the majority, $47 \%$ of the lame and handicapped who were interviewed, are earning income of less than one US dollar a day, and therefore, lived below the poverty line. This implies that, the lower incomes did not support respondents to live in houses with higher monthly rents as they spared less amount of money for house rents. As a result, they were forced to rent houses in informal settlements and in environmentally fragile areas. 


\subsubsection{House Types}

The dominant building type is the "Swahili" house with an average of six rooms, but very often more private rooms were added in the backyard and subsequently a building could have as many as twelve (12) private rooms. This idea of incremental house development in developing countries is associated with limited or unavailable housing finance [18]. The Swahili house typically had a central corridor or passage leading from a veranda facing a street to a backyard with outbuildings and to private rooms on each side. The outer building normally contained storage or cooking rooms, a bath room or pit latrine (Fig. 1). The storage and cooking rooms located at the backyard were being used by the landlord while tenants were using corridors or sitting rooms. The corridors were not spacious enough to be used by all tenants (two to three each with at least one room), food storage was sometimes done in bed rooms as some sitting rooms were used as bed rooms during the night by tenants with big families. Nguluma [19] revealed that facilities like toilets and bathrooms in the Swahili house type are provided at the backyard and each tenant occupies one or more rooms together with his/her household members. She further found that, sometimes, tenants share the house with the owner, sharing both indoor and outdoor spaces. Some
Swahili houses have been and are still being modified to make up the so called modified Swahili houses. This house type combines characteristics of conventional Swahili house type with new interior design.

The houses were modified through the addition of the head room and increasing the size of the windows. Furthermore, modification had affected the storage and cooking rooms at the backyard as they were changed into bedrooms for young boys who belonged to the landlord in order to effectively utilize the rooms in the main building for renting purposes. In other circumstances, if the landlord and his/her family were living in another area/plot without tenants or living with tenants in the same area/plot but with no male children, the storage and cooking spaces were completely changed into rental rooms. In the modification, the backyard, which was enclosed by a fencing wall, indicated that the area was for private use.

The house types were not suitable for people with disabilities particularly the lame. This is due to the fact that: some houses are built in informal areas, particularly in Buguruni ward. Accessing those houses using tri-cycles is difficult since there are no designated access roads. Typical examples include houses in Buguruni Kisiwani and Madenge sub-wards.

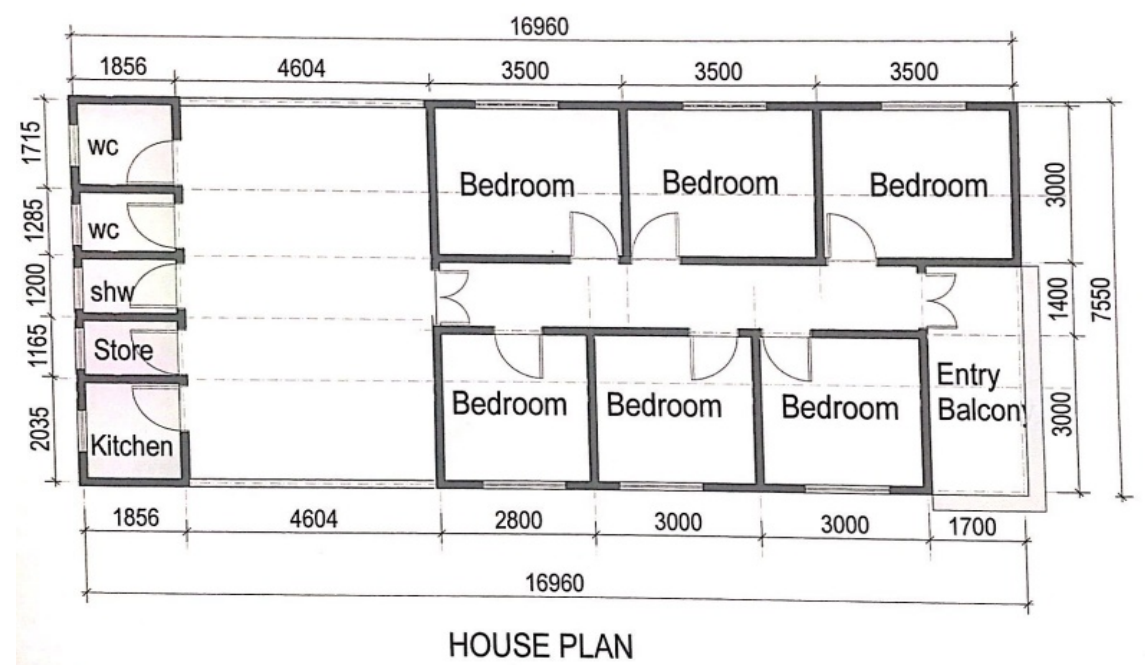

Fig. 1 Typical Swahili house. 
In these houses the housing infrastructure services are located at a distance, in this case, at the backyard. Depending on the location of the room, for the lame it is difficult to move along the corridor of the house and on the ground outside the house in order to access and use the services during the night. The corridors which were used for cooking and storage of water and charcoal limited circulation along the corridor for the lame and hence limited circulation/movement. At the same time, they were not big enough for all tenants to meet their domestic needs (cooking and storage of water). As a result, disabled and non-disabled tenants sometimes necessitated to use sitting rooms for cooking (using charcoal) and storage, which is considered dangerous in terms of health.

\subsubsection{Monthly Rental Charges}

Monthly rental charges on average ranged from TZS 25,000 to 45,000 per room depending on the type, size and location of a room(s). In Buguruni ward, the most expensive room per month was being charged at TZS 30,000 since the area was informal in nature. This amount was charged for the rooms which had electricity while those with no electricity were rented at the maximum of TZS 15,000 .

In Ilala ward, the most expensive room was rented at TZS 45,000 on average per month. The room attracting this rent was supplied with electricity. It was noted that the increase in rental charges was mainly caused by ever expanding demand. The market demand with limited supply sometimes forced physically disabled persons particularly those without regular income to move and find rental houses in peri-urban settlements such as in Vingunguti, Tabata, Kigogo and Mburahati.

It was further observed that, shortage of housing was sometimes caused by brokers who created fake shortage in order to negotiate higher rent not initially set by to get a considerable amount of money as the expected tenant(s) agree to rent a room or a house, sometimes convince landlords in order to increase their commissions. In this case, the expected tenant(s) need to pay the broker the same amount of money as that he/she is needed to pay for that room or a house as a monthly rent. Mwamasage (2009) [20] in his study on the impact of formalization of properties in informal settlements on land administration in Hanna Nassif and Ubungo Kisiwani found that, in 2009 house rent had increased from TZS 10,000 per room before settlements were formalized, to 15,000 after formalization depending on the room size. The rental charge has however recently escalated to between TZS 35,000 and 45,000 in Hanna Nassif and TZS 30,000 to 35,000 in Ubungo Kisiwani.

\subsection{Process of Accessing Rental Housing: The Common Practice}

In Dar es Salaam and wherever in fastest growing urban areas in Tanzania, the process of searching for a room, rooms or the entire house for renting has three major steps. These include meeting brokers/landlords, physical visit to the house to be rented and lastly meeting the landlord for negotiations and contract signing.

\subsubsection{Information Gathering on Housing Availability}

The process of accessing rental housing in the private housing market in Dar es Salaam starts with meeting or communicating with brokers who normally have enough information on the room such as house availability, type of house, quality, location, sometimes rent to be paid, period of paying rent and any other information concerning the rental housing. The brokers get such information from individual house owners who are willing to let out their rooms or houses. In an interview, it was observed that only 5\% used brokers in searching for and accessing rental housing. However, some owners do not provide information regarding availability of housing to brokers. Instead, they allow existing tenants to pass on information to people or friends searching for a house to rent. This occurs very rarely.

\subsubsection{Physical Visits to Houses}

Having preliminary information on availability of a 
house, the broker, or in some few cases the landlord, takes the house seeker to the house or room to see if the quality and its location match with the desires of the house seeker. For this deemed service the seeker needs to pay the broker a consultation fee between TZS 3,000 and 5,000 no matter whether or not the seeker is contented with the house qualities and if he/she is taken to another site, the same payment is payable until the seeker finds the desired house or room for renting.

\subsubsection{Meeting the Landlord}

Notwithstanding the fact that house seeker had walked with the broker in the referred two steps, if he/she is satisfied with the quality, location, size and type of the house he/she should meet the landlord. The essence of meeting the landlord is to know the amount of rent to be paid per month, the terms of payment (monthly, semi-annually or on annual basis) and any other conditions relating to the houses to be rented, estate or plot. Agreement on the terms and conditions in rare cases, signing of a tenancy contract which openly specifies the do's and don'ts by the tenant. Most agreements in these settlements are informal and hence not reduced to writing. Once an oral or written agreement is concluded, the tenant would pay the broker one month rental amount as commission.

\subsection{Accessing Rental Housing}

\subsubsection{Body Characteristics}

Body characteristics of the lame and handicapped is the major challenge in accessing rental housing as all five groups of six people each (30 respondents) agreed to it as the foremost challenge. This is due to the fact that searching for a rental house often involved a lot of walking to distant places to locate letable houses. As a matter of fact, the physically disabled people particularly the lame, normally move, crawl or use rods and the majority lack transport facilities like tri-circles. They cannot, therefore, walk long distances. In some cases, houses were located in inaccessible and environmentally hazardous areas for the lame that either crawl, use tri-circles or wheel chairs. Other stakeholders such as TTA, TAMH, CHAWATA, ILA and ICD also agreed that body characteristics were the foremost challenge in accessing rental housing. This was due to the fact that physically disabled persons find it difficult to access some areas in unplanned settlement but again brokers avoid serving people with disabilities as they may fail to pay the required fee.

\subsubsection{Affordability to Brokers}

A good number of people with disabilities, particularly the lame and handicapped, had no formal employments. They mostly relied on the informal activities and/or self employment except few that is $3 \%$ of persons interviewed. Consequently, their monthly or annual incomes were meagre and unstable to meet their immediate family requirements, including housing, a basic requirement for human life. Most disabled persons failed to meet the preliminary requirements of brokers fees for identifying requisite accommodation in the private rental housing market such as paying the so called "consultation or house verification fee" which ranged between TZS 3,000 and 5,000. This was reported as a foremost challenge, therefore, brokers normally declined to provide information on available rental housing to the lame and handicapped, hence it became for them harder to look around for rental house. One of the experienced lame former tenant, now owning a house, famously known or nicknamed as "Siasa" who is living in Buguruni, Madenge street, when narrating the reasons why the lame and handicapped did not use brokers while seeking residential premises for renting had this to say:

"Brokers are amazing people. They have made it impossible for the needy to secure rental houses in urban areas, particularly in Dar es Salaam, owing to their own pressure to sustain their daily needs. They have made it a custom that before they may take a client (a residential house seeker) to an available house, they ought to be paid between TZS 3,000 and 
5,000 (depending on the location of the house or $\operatorname{room}(\mathrm{s})$, an amount even those with no physical disability, better placed to making money cannot afford. In the circumstance a disabled person is forced to search for rooms or houses on their own even where someone could easily provide a guide. How can we, (the lame and handicapped) afford the demanded commissions while our daily meals are not guaranteed? Often we wake up in the morning uncertain of how we would sustain our families."

Six out of 10 interviewed brokers reported that about $85 \%$ of the people with disabilities could not meet broker fees. Brokers were however not willing to help the lame and handicapped to access available housing as brokers are also struggling for survival.

\subsubsection{Affordability of House Rental Charges}

The issue of affordability as a challenge in accessing rental housing in the private rental housing market was also reflected in meeting rental payment. In this case, data collected were insufficient to affirm that all tenants with physical disabilities were not capable of paying timely. $30 \%$ of respondents observed that inability to promptly pay monthly rentals was a serious challenge in accessing rental housing.

The remaining respondents mentioned low incomes as a challenge which faced them in accessing rental housing in the private housing market. One respondent, a lame, handicapped and household member said:

"It has been conceived that we (the physically disabled) are all poor. We cannot raise enough money to pay the rent set by landlords. This is because of our physical impairment, nothing else. In reality some can afford and some cannot but generally we are all denied of rental houses irrespective of the ability to pay or not."

Bramley [21] contends that people should be in a position to occupy housing that meets well established norms of adequacy at a net rent which leaves them enough income to live on without falling below some poverty standards.

\subsection{Challenges of Using Rental Housing}

The study revealed three main challenges which the lame and handicapped are facing in occupying rental houses.

3.4.1 Using a Rental Home and Housing Infrastructure

The study revealed different challenges that the lame and handicapped are facing in using a house and housing facilities. The challenges emanate from the use of outdoor environment such as the entrance and the backyard, the use of bathrooms and toilets, and the general house design(s).

\section{The Outdoor Housing Environment}

The cheapest houses which the lame and handicapped could afford were found in hazardous areas such as valleys/flood plains, which are always wet. These spaces, are environmentally dangerous for the lames particularly those with limb impairment who move by crawling due to the dirty and polluted space via domestic liquid and solid wastes.

Generally, the outdoor environments in most housing areas which harbor low income people in Dar es Salaam are very poor hygienically and have limited space for outdoor activities. This emanates from a common practice of rental housing construction in Dar es Salaam which aims at maximum utilization of land in order to get more rooms for renting. Houses are built in such a way that they align and form a rectangular or square form. As a result, a small area around the houses is left for the rest of all outdoor activities such as washing and drying of clothes and utensils generating a large amount of waste water, which is normally poured onto the space created by houses, rendering the outdoor environment wet most of the time.

\subsubsection{House Designs of Steps}

Ramps provide a smooth, slow ascent or descent that can be traversed at any length of stride [22]. In this study, it was found that houses, particularly to 
which the lame rent lacked ramps which easily facilitate the movements of such person in and outside the houses. In other words, none of the houses had considered the use of people with disabilities for efficient use of the houses. The type of steps which are being used are straight run or stairs (Fig. 2).

The study found that $87 \%$ of respondents rent houses in informal areas in valleys where houses, in terms of designs are more raised, while the rest $(13 \%)$ rent houses with depressed or no flat steps. The designs made the houses to have straight but narrow, steep or gradual steps. This implies that easily wheel-chaired and non-wheel chaired bound individuals are unable to gain entry to their houses together with their walking devices. When asked about how the house designs affected their use, a 55 years old lame tenant responded.

"It is difficult to go in and out the house we live in. It has a long depressed steps constructed to prevent water from entering the house due to floods during rain seasons. Therefore, they have highly raised foundations and the steps to the house. It is also a nightmare for a person using a tri-cycle or crawling to enter the house."

Staircases can be potential hazard for lame and handicapped persons. It is important to consider ramps in houses which may be used by people with disability.

\subsubsection{Designs of Toilets and Its Spatial Quality}

The designs of toilets in both settlements had no spatial qualities to favor the physically disabled persons, particularly the lame. They had no sitting pans to support people with disabilities while using the facilities. Instead, two raised pieces of cement blocks are placed on each side of the toilet pit for leg support. Doors are too narrow $(80 \mathrm{~cm}$ to $90 \mathrm{~cm})$ and sometimes with raised steps for challenged persons using tri-cycle or the lame find it difficult to use this type of toilet. Other toilet spaces studied were too narrow (with varying sizes) to accommodate or allow a tri-cycle to maneuver in and out.

Buguruni settlement, like many other informal settlements in the city, has no central sewerage system. The sanitation systems used by most households (87\%) are pit latrines. In these settlements, it is common for, households living on the same plot to share a common toilet and bathroom. In these settlements, among thirty homes visited, a total of three houses lacked toilets; hence residents have to use neighbours' toilet.

The water table in Dar es Salaam is relatively high

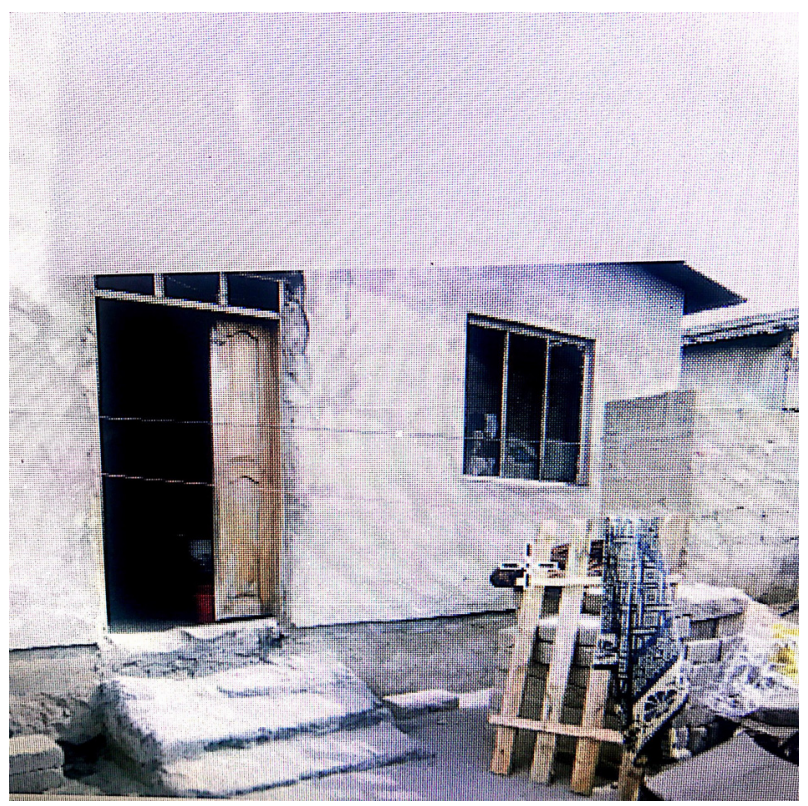

Fig. 2 A house with raised step. 
and subsequently pit latrines often overflow. Most households cannot afford hiring cesspit emptier for empting charges range from TZS 60,000 to 120,000 per trip, depending on the location and accessibility of the house. Therefore, empting is being done manually through a common local practice of digging another pit adjacent to the existing one such that the sewage is drained into the new pit and subsequently covered with excavated earth. This is locally referred to as "kutapisha", literal meaning "to cause vomiting". In reality, this method is a clear agent of water leaching creating a major challenge to the environment.

Another method used by residents is draining sewage from filled up pit into running storm water through the natural drains, especially when it rains. These practices are obviously unhygienic and enhance vulnerability to communicable diseases and other health impacts to the residents and community around the settlements under discussion.

\subsubsection{Toilet Environments and Use Constraints}

In the cause of the study it was further noted that most plots have a number of rental rooms ranging from six to ten or twelve. The availed toilets in most cases pit latrines are also used for bathing. Often, tenants share the bathrooms and toilets with the landlord family. In few instances tenants have their own bathroom and toilet. Construction of bathrooms in these areas constructed by local artisans provided inadequate slope to drain water into the toilet hole or a rear outlet to unplanned land surface. As a result, occupies take shower, water drains outside the bathroom to the backyard through the entry point. Entry points to the described toilets are largely covered by a piece of cloth, sack or piece of iron sheet over a wooden shutter. The wooden shutters easily rot due to moisture rich in salt and urea. Consequently, water easily spread out to the surrounding environment creating wetness during peak bathing hours that is mornings and evenings. This practice pollutes the rented environment.

Another challenge in the use of this kind of housing facility is general bathrooms cleanliness. The lame sometimes fail to use bathrooms because of soap lather left out, necessitating removal of the same, first by pouring some water on to the area or decking the floor before using the bathroom. These (toilets and bathrooms) remain wet most of the time; therefore require higher degree of hygiene including wearing of sandals or shoes. In case of disabled persons who have to move by crawling they are unable to take advantage of the rudimentary protection measures, hence succumb to the dirty surface having to use bare hands. To ensure hygiene in these areas, each tenant is usually obligated to clean the bathroom and toilet at least once a week. By the time cleanliness is done however, the disabled would have endured the risk to infection via the unhygienic environment.

3.4.6 Unhealthy Queues for Toilets or Bathrooms during Peak Hours

The study reveals that early in the morning when people are bound to leave their homes for work and during evenings before retiring to sleep, tenants have to queue for toilet or bath facilities occasionally one room for a number of occupants. Queuing for toilet is more tortuous for the disabled compared to those who have no physical impairment who can, when times are difficulties, move around for alternative facility.

\subsection{Strategies to Overcome the Challenges of Accessing Rental Housing}

This study, amongst others, has revealed that the process of accessing rental housing by the lame and handicapped in Ilala and Buguruni wards, except in few cases, did not involve the brokers in contrast to what is above, but rather four other actors. These included: the lame and handicapped who either used landlord(s), other tenants, non-disabled people and referee(s)/guarantor(s). Persons of given rental premises with disability, who were rental housing seekers, either used the tenants or faced the landlord directly. In most instances a middle person, served as a catalyst or "referee", who also ensured realization of 
the rental space. The brokers were not involved in this case for the reason already stated whereby (brokers) shun away from disabled persons due to failure to adhere to the brokers' fees. Findings showed that only $5 \%$ of disabled persons used brokers in searching and accessing rental housing.

\subsubsection{Meeting Landlords Directly}

Residential house/room seeker met a landlord directly. According to the study findings only $20 \%$ of the interviewees met landlords directly while searching for rental houses as they could not afford brokers. The disabled role in this aspect was to search for rental housing information as diligently as they could from different people and in different locations. The rental space owners, in this case landlords, had the discretion to accept or reject an offer to rent out a room, rooms or a house if the space seeker failed to adhere to regulations or conditions set. The conditions could be marital status or size (married, married without families or unmarried), occupation and terms of paying the rent set. As long as the lame and handicapped approached the landlords seeking residential rental spaces, either by being tipped by existing tenants or from friends, the major issue considered was the ability of the would be tenant to pay the set rent, although other social issues such as past relationship with some of the tenants or the landlord himself were reviewed. The common condition was payment of rent promptly on six months duration or once annually; parallel with this to have a referee who would be held liable if the tenant fails to pay the rent. However, only $3.3 \%$ of the persons we interviewed were guaranteed by third parties in their tenant tenure.

3.5.2 Using Existing Tenants, Relatives and Friends

"Existing tenants" meant those currently renting rooms or house owned by the landlord who happens to have other vacant room, rooms or a house to let. This strategy was adopted by 33 respondents out of 60 (55\%) in accessing rental housing. By knowing the hurdles which the lame and handicapped faced in the process of searching for residential homes, they pitied and secretly passed information to room or house seeker who had a physical disability. In most cases, people who do this are normally friends or close relatives who have information regarding the person in search for a residential rental space.

3.5.3 Using a Non-disabled Person as a House Seeker

As discussed above, $60 \%$ of the brokers interviewed expressed unwillingness to engage with the lame and handicapped in providing information on the availability of rental housing on the grounds that the latter were unable to pay the so called "house search/verification/consultation fee". In some instances, landlords decline offers to rent their houses to the lame and handicapped because of the fear that the disabled person may not have the ability pay the monthly, semi-annual or annual house set rent. The study results reveal that $21.7 \%$ of the lame and handicapped use non-disabled people in searching for rental houses.

\subsection{Strategies Adopted in the Use of Housing Infrastructure}

3.6.1 Cleaning before Using Bathrooms/Toilets before Use

The study reveals that in cases where non-disabled tenants improperly used toilets and bathrooms by leaving out soap lather, faecal matters or urine drops on the floor, $100 \%$ of the lame tenants most frequently cleaned and dried up the floor before using the facilities. This was due to the fact that their hands are bound to touch the floor when using facilities. This is an unfortunate situation given the physical condition of the disabled either the lame/handicapped himself/herself, asking/requesting a non-disabled tenant or when helped by one of the family members. In responding to this challenge, one said:

“... If you cannot clean the facilities, you are not liable for the use. In reality some non-disabled tenants are not happy about this. When it happens so, we do it 
by ourselves....I think you know what I mean.......It takes so long to complete and sometimes we fail to do it, particularly in toilets and bathrooms."

The statements above show that sometimes the lame and handicapped are obliged to clean toilets when they need to use them despite the fact that the cleaning duty is not their turn. On failures to clean they use the toilets while unclean, and this happens when the non-disabled tenants especially children are away or if available decline cleaning.

\subsubsection{Putting on Slippers}

Another strategy in overcoming this challenge is putting on slippers covering their hand palms and $75 \%$ of the lame used this strategy. However, this did not guarantee the rest of their body parts such as legs and knees to escape from touching the dirty floors of bathrooms and toilets.

\subsubsection{Using Wooden Furniture}

The study revealed that $25 \%$ of the lame used wooden furniture in overcoming the dirty environments in toilets and bathrooms mainly caused by non-disabled tenants who haphazardly used the commonly shared housing facilities or while bathing. The interview with a lame all his life time, now a landlord, aged 60 years contended that furniture mainly used is wooden chairs commonly known as stools. Others sat on slippers as a technique to overcome the dirty environments. This adaptation was typical to the lame that could not properly use the pit latrines or bathrooms due to their physical nature, lack of legs or stability to support their bodies while using the facilities. In responding to the challenges of using bathrooms/toilets, an experienced lame tenant and landlord based in Mafuriko sub-ward in Ilala ward was quoted saying:

"I, myself, use a stool while taking shower or attending call of nature. I think most use this method in order to get rid of the contamination in toilets and bathrooms as well."

According to $\mathrm{CMHC}$ [23] reinforced mounting points for grab bars, adequate space for wheelchairs, and possible roll in showers with adjustable heights are to be considered in houses to be used by the people with disabilities.

\subsubsection{Waiting or Taking Shower during the Night}

With regard to queuing in using the facilities, particularly during the morning when the majority needed to use the facilities, the lame and handicapped rarely did it. Instead, they waited until all had used them and afterwards they used the facilities. When a lame woman was interviewed, she attested to take bath only during the night in order to avoid being observed by other tenants on the hurdles she normally face during entering the bathroom and toilet. The woman remarked: "We can't queue when our fellow non-disabled tenants need to use the toilet and bathrooms, particularly during the peak hours in the morning."

CMHC [24] observed that there is a need to have a different approach to housing for people of all calibres and all levels of ability to live comfortably and independently. To also access basic services comfortably.

\section{Emerging Issues}

\subsection{Affordability Levels and Associated Consequences}

Findings from the study revealed that due to rapid increase and irregularly changing monthly house rents as a decision of landlords and sometimes brokers, the affordability level of the lame and handicapped is low. This is, however, backed up by the nature of activities, these people carry out to support their living which are selling small items along bus stops and in Mchikichini small scale businessmen/women market. Issues of house rent payments and other basic life requirements are highly constrained by their low incomes. As a matter of fact, a complicated system to access rental houses in Dar es Salaam (the use of middle men/brokers) which is not guided by any legal document or procedures makes it more costly for the lame and handicapped to afford all the associated costs to realize a rental residential space easily in 
areas which have good qualities for healthy living. As a result of this, the lame and handicapped are forced to move to poor shelters such as in valleys which are in most cases vulnerable to flood. Under rent control, households of different income levels enjoy protection [24].

\subsubsection{Space Use and Privacy}

Public spaces in most privately owned rental houses such as cooking, toilets and bathrooms are commonly shared among tenants and in some cases with the landlord(s). Given that rental housing has been made a business in urban areas by landlords, there is always a high density of houses in the same plot to maximize rental space. This reduces space for other indoor and outdoor activities. Moreover, other private spaces for toilets (pit latrines) and bathrooms are greatly narrowed and accommodated in a single room, resulting into sharing of sanitary facilities which lack hygiene due to improper use of the facilities as well as lack of cleanliness. This is a common problem, particularly for the lame and handicapped who are sometimes inferior over the non-disabled tenants in using these facilities.

On the issue of privacy, it is evident that bathrooms or toilets are more raised up than the living spaces because of high water table in Dar es Salaam. But these important facilities in human life lack proper doors and roofs; only pieces of sacks or clothes are used to cover door openings, the situation that reduces privacy in using the facilities particularly by the lame that in most cases need to be in contact with floor while using the toilets. Sharing bathrooms and toilets with landlords do not provide enough space to enable tenants both disabled and non-disabled in accessing their own private (household) services instead of sharing the same with landlords or other households with no disabilities. This situation aggravates isolation or stigma for the lame and handicapped which is against the fundamental human rights. Attention to this issue needs to be brought to light of the concerned authorities for policy action.

\subsubsection{Legal or Policy Framework}

Presently there are no specific government policies, whether restricted or National on Disability or a regular framework which take on board access to rental housing issues for the lame and handicapped or people with disabilities in general. This is a serious omission taking into consideration that housing is a primary need of all people the lame and handicapped inclusive. The latter category belongs to vulnerable people who require certain priorities to make their livelihood meaningful. An immediate solution towards this anomaly is to correct the prevailing situation.

\section{Conclusion}

Accessing rental housing by the lame and handicapped in fast growing urban areas, such as in Dar es Salaam, where housing is an ever growing is a complex phenomenon. This is due to the absence of legal regulatory framework pertaining to accessing housing. This includes the absence of procedures to be adhered to in accessing rental housing as well as binding rules or regulations in setting up rents. Exacerbated by government failure to provide social/public rental housing, private individuals construct commercial houses for renting purposes as an income/ livelihood strategy. This gives landlords/ladies power and room to set up rents which do not reflect the financial capacity of a majority of urban dwellers, the lame and handicapped inclusive. There are shifting trends for the lame and handicapped inability to pay house verification fees demanded by brokers and house rentals due to unrealistic rentals set by landlords/landladies often raised by brokers (madalali). This trend is expected to persisting for long if no measures are taken to counteract the problem. With regard to the lame and handicapped a majority of them are willing to pay set rentals but some are refused on the account of social stigma (direct discrimination). To address the issue pointed out above, there is a need for intervention by the 
government by putting in place policies to address easy access to rental housing by the lame and handicapped or generally the physically disabled people. This can be done by putting housing demand among the top priority, putting up a framework for strengthening the institutions dealing with housing to institute special priority to persons with disabilities; and similarly, human rights institutions to address stigmatization of the lame and handicapped.

\subsection{Recommendations}

\subsubsection{Process of Accessing Private Rental Housing}

There is a need for the government to regulate brokers so as to ensure that the latter would adhere to certain regulations in the course of searching for residential rental houses, for their customers including when and how they should charge for their services. Rentals levied for residential accommodation should be regulated to consider all income level groups and body characteristics in order to provide equal chances to all groups in securing rental homes. As already discussed the prevailing approach has no regulatory mechanism particularly on the payments that brokers demand in providing information on the availability of rental housing and the physical verification of the house identified for customers. Currently brokers charge for merely identifying a house to a customer whether or not the customer will ever reach an agreement with the owner.

\subsubsection{Rent Control}

After the abolition of the Rent Restriction Act of 1984 in 2005, there has not been any other rent regulatory body or regulation to control or even provide a guide on rent setting for residential private houses in the country. Consequently rental charges have been left out to be regulated by the supply and demand phenomenon. Inevitably, there has been a tremendous increase of monthly rental charges in the private housing market in Dar es Salaam which is mainly caused by urban migration of the rural population hence an ever increasing demand for residential housing. Monthly rents for housing in both planned and unplanned areas are set by landlords/ladies house renting being profitable businesses. This social economic development has dire consequences to the lame and handicapped who find it very hard to find decent affordable housing. Stakeholders who are keen to assist the lame and handicapped like the TTA have suggested that there should be a regulatory body or any other legal regulatory mechanism to control house rents. Monthly house rents should be set by considering the location of the house (in formal or informal areas). The other determining factors should be income levels, room size or space and body characteristics (disabled or non-disabled).

\section{References}

[1] Junaid, A., Aasif, Y., and Shahid, M. 2017. "Rental Housing Management System." International Journal of Computer Sciences and Mobile Computing 6 (7): 1-4.

[2] UN-Habitat. 2001. "Everyone Deserves a Decent Place to Live.” Urban Millennium.

[3] UN-Habitat. 2011. "Rental Housing: A Much Neglected Housing Option for the Poor." Housing the Poor in African Cities, Nairobi.

[4] Greg, S. 2015. "Rental Housing Dynamics and Lower Income Neighborhoods in Canada." Research Paper of University of Toronto.

[5] Komu, F. 2008. "Quality Housing and Its Influence on Consumer's Behavior." Paper presented on the Construction and Building Research Conference of the Royal Institution of Chattered Surveyors, Dublin Institution of Technology.

[6] Bank of Tanzania. 2018. "Guidelines and Standards for Affordable Housing in Tanzania, Dar es Salaam.” Bank of Tanzania.

[7] National Housing Corporation (NHC). 2004. "Analysis of Housing Problems in Tanzania National Housing Corporation." Dar-es-salaam, NHC.

[8] Stanley, J. N. F. 2007. Access to Decent Housing by HIV/AIDS Victims in Tanzania. Post dissertation report, unpublished.

[9] UNCHS. 2009. Planning Sustainable Cities. A Global report of a Human Settlements, United Nations Human Settlements Programme, Nairobi.

[10] UNCHS. 2002. "The State of the Worlds Cities 2001 Habitat." United Centre for Human Settlements, Nairobi. 
[11] United Republic of Tanzania (URT). 2000. The National Human Settlements Development Policy. Government Printer, Tanzania.

[12] Sheuya, S. 2004. Housing Transformations and Urban Livelihood in Information Settlements (No. 45). Dortmund: Spring Research Series.

[13] United Republic of Tanzania (URT). 1995. National Land Policy. Government Printer, Dar-es-salaam.

[14] WHO. 2011. World Report on Disability. World Health Organization, Geneva.

[15] United Republic of Tanzania (URT). 2004. National Policy on Disability. Government Printer, Dar-es-salaam.

[16] United Republic of Tanzania (URT). 2010. The Person with Disabilities Act. Government Printer, Dar-es-salaam.

[17] Sangiwa, E. R. 2007. Planning for Public Transport for the People with Disabilities. An undergraduate dissertation report.

[18] Mukhija, V. 2014. "The Value of Incremental Development and Design of Affordable Housing." Journal of Policy Development and Research 16 (2): 11-20.

[19] Nguluma, H. 2003. Housing Themselves; Transformation, Modernization and Spatial Qualities in Informal Settlements in Dar-es-salaam. Tanzania: KTH Stockholm.

[20] Mwamasage, C.D. (2009). Impact of Formalization of Properties In Informal Settlements on land Administration. Post Graduate Dissertation Report, Unpublished.

[21] Bramley, G. 1990. Equalization Grants and Local Expenditure Needs: The Price of Equality. Aldershot: Avebury.

[22] Olof, H., Bengt, J., Johan, M., and Rasmus, W. 2009. The Complete Guide to Architecture in Stockholm. Stockholm: Kristianstads Boktryckeri AB.

[23] Canada Mortgage and Housing Corporation (CMHC). 2010. "Accessible House by Design.” House Design and Floor Plans.

[24] Canada Mortagage and Housing Corporation (CMHC). 2013. "Creating Housing and Communities for All Ages." The Principles of Universal Design, Designing Project. 